\title{
Description of Christensenella minuta gen. nov., sp. nov., isolated from human faeces, which forms a distinct branch in the order Clostridiales, and proposal of Christensenellaceae fam. nov.
}

\author{
Masami Morotomi, Fumiko Nagai and Yohei Watanabe
}

Correspondence

Masami Morotomi

masami-morotomi@yakult.co.jp

The use of culture-independent molecular methods to analyse the gastrointestinal (GI) microbiota has allowed a more complete and accurate assessment of the biodiversity of this ecosystem (Eckburg et al., 2005; Ley et al. 2008; Turnbaugh et al., 2009; Tap et al., 2009; Qin et al., 2010). Such molecular methods using small-subunit rRNA gene sequence-based technologies are considered fruitful for finding potential links between microbes and a certain health and/or disease status. However, as pointed out by Zoetendal et al. (2008), it has to be realized that the results obtained with such approaches cannot necessarily be extrapolated beyond the description of the microbial diversity, since potential functions of these microbes are not always extracted from small-subunit rRNA gene sequence data. At the moment, although links have been

Abbreviations: $\mathrm{A}_{2} \mathrm{pm}$, diaminopimelic acid; Gl, gastrointestinal; $\mathrm{ML}$, maximum-likelihood; MP, maximum-parsimony.

The GenBank/EMBL/DDBJ accession number for the 16S rRNA gene sequence of strain YIT $12065^{\top}$ is AB490809.

A supplementary table is available with the online version of this paper. elucidated between the intestinal microbiota and GI tract disorders, causal effects have been determined only for cultured bacterial species such as Helicobacter pylori and Clostridium difficile. This observation, and the fact that the recent study of Eckburg et al. (2005) reported that the proportion of reported cultivable bacteria was only $20 \%$ for the human intestinal microbiota, indicated that cultivation of novel GI-tract inhabitants is indispensable for future studies of links between microbes and GI tract diseases such as inflammatory bowel diseases (IBD) and irritable bowel syndrome (IBS).

To understand better the physiological characteristics and function of the majority of the human GI microbiota, we have performed several intensive cultivation trials aimed at isolating so-called 'unculturable' or 'as-yet-uncultured' bacteria from the human GI tract (Sakon et al., 2008; Morotomi et al., 2008, 2009, 2010, 2011; Nagai et al., 2009, 2010a, b; Watanabe et al., 2010). Among these bacteria, 15 strains of 15 novel species including three new genera were adopted as reference genomes by the Human Microbiome Project (http:// www.hmpdacc.org/reference_genomes/reference_genomes. 
php) and the assembled and annotated genomic sequences of these bacteria will be submitted to GenBank. In this article, we report the characterization and classification of strain YIT $12065^{\mathrm{T}}$, proposing its affiliation to a new family, genus and species.

Faecal samples were collected from two healthy Japanese males (subjects $\mathrm{H}$ and $\mathrm{K}$, aged 57 and 27 years, respectively) and transferred immediately to anaerobic conditions. Each sample was weighed and diluted with prereduced 0.1 M PBS ( $\mathrm{pH} 7$ ) in an anaerobic glovebox (Coy Laboratory Products), which contained $88 \%$ nitrogen, $7 \%$ hydrogen and $5 \%$ carbon dioxide. Each dilution was then spread on modified Gifu anaerobic medium (GAM; Nissui Pharmaceutical) containing $1.5 \%(\mathrm{w} / \mathrm{v})$ agar that was supplemented with bile $(2,4,6$ and $8 \%$ Bacto oxgall; Difco), $\mathrm{NaCl}(1,3,6$ and $10 \%, \mathrm{w} / \mathrm{v}$ ) or antibiotics (one of 12 compounds, at three different concentrations) in an attempt to isolate subdominant groups of the intestinal microbiota. The composition of the modified GAM agar was described previously (Sakon et al., 2008). The inoculated plates were incubated at $37^{\circ} \mathrm{C}$ for 3 days in an anaerobic glovebox. Subsequently, colonies showing different morphologies were selected and subcultured on GAM agar to obtain pure cultures. Strain YIT $12065^{\mathrm{T}}$ was isolated from a GAM agar plate $(\mathrm{pH} 6.8)$ supplemented with $8 \%$ Bacto oxgall (equivalent to $80 \%$ bile) inoculated with a $10^{-6}$ serially diluted faecal sample from subject $\mathrm{H}$.

The end products of strain YIT $12065^{\mathrm{T}}$ grown in pre-reduced peptone-yeast extract (PY) medium (Holdeman et al., 1977) supplemented with $1 \%$ glucose (PYG), lactate or succinate were analysed by HPLC as described previously (Chonan et al., 1995). Carbohydrate fermentation tests and other biochemical tests, such as indole production, urease activity and hydrolysis of gelatin and aesculin, were performed by the methods described by Holdeman et al. (1977) and by using the API 20A anaerobic test kit (bioMérieux). Additional enzyme activities were determined in duplicate by using the API Rapid ID32A and API ZYM systems (bioMérieux) according to the manufacturer's instructions. Oxidase activity was determined with oxidase test strips (Eiken Chemical). Sensitivity to bile and $\mathrm{NaCl}$ was determined by comparing growth on modified GAM agar with and without $2 \%$ Bacto oxgall (Difco) or 1, 2, 3, 5, 10 or $20 \% \mathrm{NaCl}$ after 5 days of incubation at $37{ }^{\circ} \mathrm{C}$. Growth on modified GAM agar at different temperatures was assessed over time for 14 days at $15,20,25,30,34,37,40,43$ and $45{ }^{\circ} \mathrm{C}$ under anaerobic conditions by use of an AnaeroPak system (Mitsubishi Gas Chemical). The effects of $\mathrm{pH}$ on growth were determined over the range $\mathrm{pH} 4.0-10.0$ at intervals of $0.5 \mathrm{pH}$ units using $\mathrm{HCl}$ and $\mathrm{NaOH}$ to adjust the $\mathrm{pH}$ after cultures had been incubated at $37^{\circ} \mathrm{C}$ for 3 days, under anaerobic conditions with nitrogen to limit undesirable changes in $\mathrm{pH}$ during incubation.

Cellular fatty acids, isoprenoid quinones, cell-wall amino acids and whole-cell sugars were prepared from cells grown on PYG agar at $37^{\circ} \mathrm{C}$ for 3 days. Cellular fatty acid methyl esters were obtained from lyophilized cells by saponification, methylation and extraction using the method of Miller (1982) with minor modifications (Kuykendall et al., 1988). Fatty acid methyl esters were identified by using the MIDI system with MOORE5 from the MIS Standard Libraries. Isoprenoid quinones were extracted as described by Komagata \& Suzuki (1987) and analysed by using an HPLC atmospheric pressure chemical ionization (APCI)MS/MS system (API 3200; Applied Biosystems) with an Lcolumn ODS $(2.1 \times 150 \mathrm{~mm}$; Chemicals Evaluation and Research Institute) and an HPLC-APCI-MS system (Micromass ZQ equipped with 2996 photodiode array detector; Waters) with a Cadenza CD-C18 column $(3.0 \times 150 \mathrm{~mm}$; Imtakt), following the modified method of Katsuta et al. (2005). Isolation of the cell-wall fraction and preparation of the cell-wall hydrolysate were carried out by using the method of Schleifer (1985). The amino acid composition of the cell-wall hydrolysate was determined by using an Aquity ultraperformance liquid chromatography system (Waters). Whole-cell sugars were determined by HPLC [Shimadzu LC20A system; Symmetry 300 TM C18 column $(4.6 \times 250 \mathrm{~mm})]$ according to the method of Honda et al. (1989). The DNA $\mathrm{G}+\mathrm{C}$ content was determined by hydrolysing the DNA enzymically and quantifying nucleosides by HPLC according to the method of Ezaki et al. (1990).

Caldicoprobacter oshimai DSM $21659^{\mathrm{T}}$ and Tindallia californiensis DSM $14871^{\mathrm{T}}$, purchased from the DSMZ (Braunschweig, Germany), and Clostridium ganghwense JCM $13193^{\mathrm{T}}$, purchased from the JCM (Wako, Japan), were used as reference strains.

Closely related sequences were retrieved from GenBank/ EMBL/DDBJ by using the FASTA program (Lipman \& Pearson, 1985). Sequences were aligned and used to produce an unrooted phylogenetic tree according to the neighbourjoining method (Saitou \& Nei, 1987) using CLUSTAL_X (version 1.83) (Thompson et al., 1997). The stability of groupings was estimated by bootstrap analysis (1000 replications). Trees were visualized by using the TreeView program (version 1.6.6) (Page, 1996). Maximum-parsimony (MP) and maximum-likelihood (ML) methods were used to confirm the phylogenetic placement of the aligned sequences. MP analysis was performed using the software package MEGA4 (Tamura et al., 2007). The ML tree was constructed via the PHYML program (Guindon \& Gascuel, 2003) using Kimura's two-parameter nucleotide substitution model (Kimura, 1980). The input file was prepared via the SEQBOOT program in the PHYLIP software package (Felsenstein, 2004).

Cells of strain YIT $12065^{\mathrm{T}}$ were Gram-reaction-negative, non-motile, short, straight rods with tapered ends $(0.4 \times 0.8-1.9 \mu \mathrm{m})$. Electron microscopy of ultrathin sections revealed a Gram-negative cell-wall structure (Fig. 1). Growth was observed under strict anaerobic conditions but not aerobic or microaerobic conditions created by use of the CampyPak Plus system (with $5-15 \% \mathrm{O}_{2}$ and 5-12\% $\mathrm{CO}_{2}$; BBL). After 4 days of anaerobic incubation at $37{ }^{\circ} \mathrm{C}$ on modified GAM agar, Wilkins-Chalgren anaerobe agar 


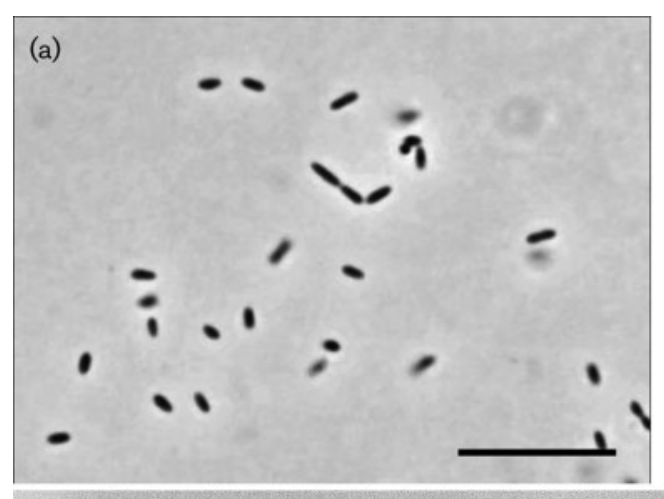

(b)

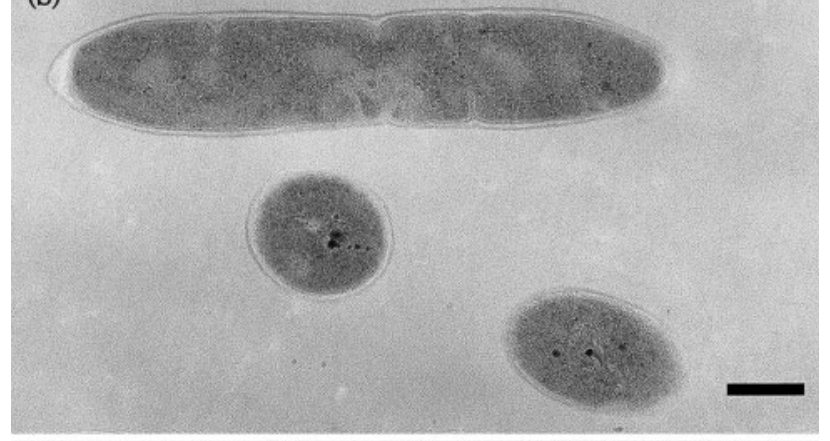

(c)

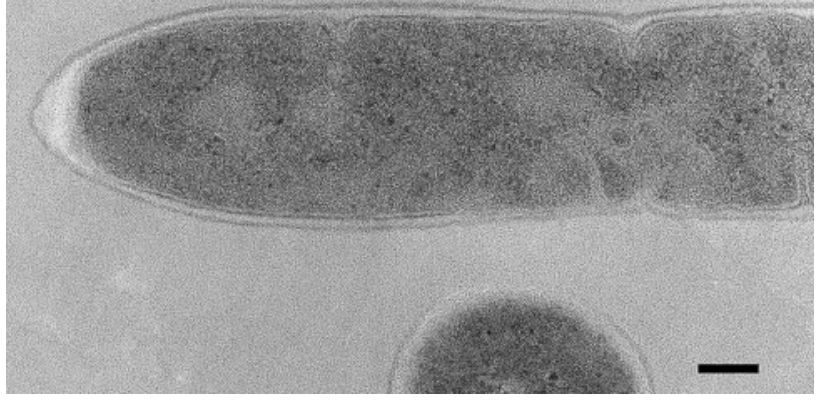

Fig. 1. Morphology of strain YIT $12065^{\top}$. For transmission electron microscopy, cells were fixed in $2.5 \%(\mathrm{w} / \mathrm{v})$ glutaraldehyde, postfixed in $1 \%(\mathrm{w} / \mathrm{v}) \mathrm{OsO}_{4}$, dehydrated in a graded ethanol series and embedded in Epon 812 resin. Ultrathin sections were cut in an ultramicrotome (Reichert-Nissei), loaded onto nickel grids and stained with $2 \%(\mathrm{w} / \mathrm{v})$ uranyl acetate and Reynolds' lead citrate. Samples were examined using a JEOL JEM-1200EX operating at $80 \mathrm{kV}$ accelerating voltage. (a) Phase-contrast micrograph. (b) TEM image of ultrathin-sectioned cells. (c) Enlargement of (b), showing the cell-wall structure. Bars, $10 \mu \mathrm{m}$ (a), $250 \mathrm{~nm}$ (b) and $100 \mathrm{~nm}$ (c).

[Wilkins-Chalgren anaerobe broth (Oxoid) with 1.5\% agar] or Schaedler anaerobe agar [Schaedler anaerobe broth (Oxoid) with $1.5 \%$ agar], colonies were punctiform, $0.1 \mathrm{~mm}$ in diameter, circular and beige. Strain YIT $12065^{\mathrm{T}}$ was saccharolytic. Tests for aesculin hydrolysis, gelatin hydrolysis, indole production, nitrate reduction and catalase, oxidase and urease activities were negative. Cells were resistant to $20 \%$ bile. Under anaerobic conditions, growth was most rapid at $37-40{ }^{\circ} \mathrm{C}$, slightly weak at $34{ }^{\circ} \mathrm{C}$, weak at $25-30{ }^{\circ} \mathrm{C}$ and scant at $43{ }^{\circ} \mathrm{C}$. No growth was observed below $20{ }^{\circ} \mathrm{C}$ or at $45{ }^{\circ} \mathrm{C}$. The $\mathrm{pH}$ range for growth was $\mathrm{pH}$ 6.0-9.0, with optimal growth at $\mathrm{pH}$ 7.5. Numbers of colonies grown on medium containing 1,2 and $3 \% \mathrm{NaCl}$ were 80,27 and $6 \%$, respectively, compared with control medium without $\mathrm{NaCl}$. No growth was observed on medium containing $\geqslant 5 \% \mathrm{NaCl}$. Growth of strain YIT $12065^{\mathrm{T}}$ in liquid media was very weak. Small amounts of acetic $(3.6 \mathrm{mM})$ and butyric $(0.3 \mathrm{mM})$ acids were produced as end products of glucose fermentation in PYG broth. Addition of lactate or succinate did not enhance growth or the production of short-chain fatty acids. In the API Rapid ID $32 \mathrm{~A}$ and API ZYM test systems, strain YIT $12065^{\mathrm{T}}$ was positive for $\alpha$-arabinosidase, $\beta$-galactosidase, $\beta$-glucosidase, glutamic acid decarboxylase and naphthol-AS-BI-phosphohydrolase. Other biochemical characteristics obtained by using the API systems (API Rapid ID32A, API ZYM and API 20A) are included in the species description.

Cellular fatty acid profiles of strain YIT $12065^{\mathrm{T}}$ and the type strains of phylogenetically related species are shown in Supplementary Table S1, available in IJSEM Online. Respiratory quinones were not detected. The cell wall contained glutamic acid, serine, alanine and LL-diaminopimelic acid ( $\mathrm{LL}-\mathrm{A}_{2} \mathrm{pm}$ ). Although LL- $\mathrm{A}_{2} \mathrm{pm}$ is found mainly in species of Gram-positive bacteria, some Gram-negative bacteria such as Syntrophomonas species (Zhang et al., 2004, 2005) and Desulfosporosinus species (Stackebrandt et al., 2003; Ramamoorthy et al., 2006; Vatsurina et al., 2008) have been reported to possess LL- $\mathrm{A}_{2} \mathrm{pm}$ as a diagnostic peptidoglycan diamino acid. All of these species are members of the order Clostridiales. The whole-cell sugars were ribose, rhamnose, galactose and glucose. The DNA $\mathrm{G}+\mathrm{C}$ content of strain YIT $12065^{\mathrm{T}}$ was $51.3 \mathrm{~mol} \%$.

A $1497 \mathrm{bp}$ region of the $16 \mathrm{~S}$ rRNA gene of strain YIT $12065^{\mathrm{T}}$ was sequenced. Database searches revealed that strain YIT $12065^{\mathrm{T}}$ was most closely related ( $\geqslant 86 \% 16 \mathrm{~S}$ rRNA gene sequence similarity) to Caldicoprobacter oshimai JW/HY$331^{\mathrm{T}}(86.9 \%)$, Tindallia californiensis DSM $14871^{\mathrm{T}}(86.3 \%)$ and Clostridium ganghwense JCM $13193^{\mathrm{T}}$ (86.1\%). Both Tindallia californiensis and Clostridium ganghwense belong to the family Clostridiaceae, whereas Caldicoprobacter oshimai is proposed to belong to a novel family Caldicoprobacteraceae, consisting of a single genus and species, within the order Clostridiales. Although Caldicoprobacter oshimai, Clostridium ganghwense and Tindallia californiensis are phylogenetically most closely related to strain YIT $12065^{\mathrm{T}}$, they are significantly different from strain YIT $12065^{\mathrm{T}}$ in their physiological characteristics (Table 1). Strain YIT $12065^{\mathrm{T}}$ showed even lower similarities $(79.2-85.0 \%)$ to members of all other type genera of the families within the order Clostridiales (Fig. 2).

The $16 \mathrm{~S}$ rRNA gene sequence of strain YIT $12065^{\mathrm{T}}$ shared highest sequence similarities with uncultured faecal 
Table 1. Major characteristics of strain YIT $12065^{\top}$ and type strains of related species

Strains: 1 , YIT $12065^{\mathrm{T}} ; 2$, Caldicoprobacter oshimai DSM $21659^{\mathrm{T}} ; 3$, Tindallia californiensis DSM $14871^{\mathrm{T}} ; 4$, Clostridium ganghwense JCM $13193^{\mathrm{T}}$. Data are from the present study unless indicated. All strains are strictly anaerobic and negative for catalase, oxidase and urease activities. In API ZYM tests, all strains are negative for esterase (C4), esterase lipase (C8), lipase (C14), leucine arylamidase, valine arylamidase, trypsin, chymotrypsin, $\alpha$-galactosidase, $N$-acetyl- $\beta$-glucosaminidase, $\alpha$-mannosidase and $\alpha$-fucosidase.

\begin{tabular}{|c|c|c|c|c|}
\hline Characteristic & 1 & 2 & 3 & 4 \\
\hline Isolation source & Human faeces & Sheep faeces & Alkaline lake sediment & Tidal flat sediment \\
\hline Morphology & Rods & Straight to curved rods & Slightly curved rods & Rod-shaped \\
\hline Motility & - & - & + & + \\
\hline Spore formation & - & + & + & + \\
\hline Temperature range (optimum) $\left({ }^{\circ} \mathrm{C}\right)$ & $25-43(37)$ & $44-77(70)^{a}$ & $10-48(37)^{b}$ & $15-40(35)^{c}$ \\
\hline $\mathrm{NaCl}$ or sea salt requirement & - & - & $1-20 \% \mathrm{NaCl}^{b}$ & $1-9 \%$ sea salts ${ }^{c}$ \\
\hline DNA G $+\mathrm{C}$ content $(\mathrm{mol} \%)$ & 51.3 & $45.4^{a}$ & $40.2 \pm 0.1^{d}$ & 31.6 \\
\hline Indole production & - & - & + & + \\
\hline Gelatin hydrolysis & - & - & - & + \\
\hline Aesculin hydrolysis & - & - & - & + \\
\hline \multicolumn{5}{|l|}{ API ZYM tests } \\
\hline$\beta$-Glucosidase & + & + & - & - \\
\hline
\end{tabular}

${ }^{\star}$ Data taken from: $a$, Yokoyama et al. (2010); b, Pikuta et al. (2003); c, Kim et al. (2006); d, Whitman (2006).

bacteria derived from studies of human (uncultured clone RL385_aao81d07, collected in the USA, GenBank accession no. DQ804839, 98.6\% similarity; Ley et al., 2006) and dugong (uncultured clone dgD-165 from Dugong dugon,
96.7\% similarity, GenBank accession no. AB264080; Tsukinowa et al., 2008) (Fig. 2). Based on their similar sources of isolation and 16S rRNA gene sequences, strain YIT $12065^{\mathrm{T}}$ and unidentified clone RL385_aao81d07

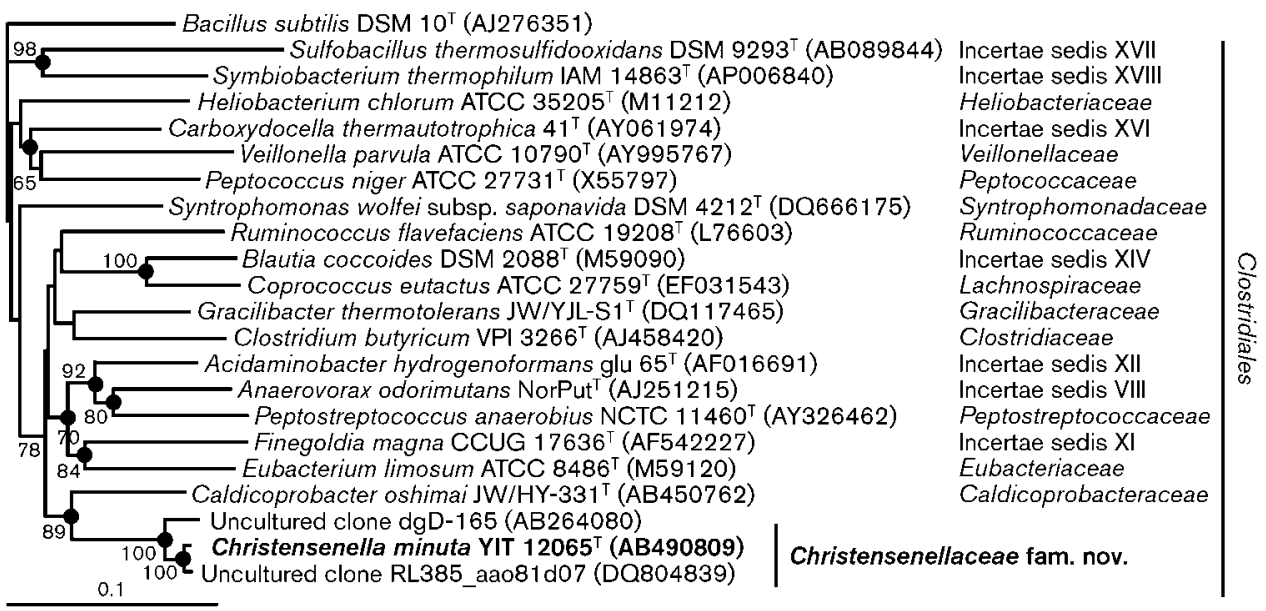

Fig. 2. Phylogenetic tree showing relationships between strain YIT $12065^{\top}$ and related taxa in the order Clostridiales based on 16S rRNA gene sequence analysis. The tree was rooted with Bacillus subtilis DSM $10^{\top}$ and was reconstructed by using the neighbour-joining method and based on a comparison of 1170 nucleotide positions, with bootstrap values ( $>50 \%)$ expressed as percentages of 1000 replications. Similar tree topologies were obtained by using the MP and ML methods (not shown). Filled circles indicate that the corresponding nodes were also recovered in trees generated with the MP and ML methods. GenBank/EMBL/DDBJ accession numbers are shown in parentheses. Bar, 0.1 substitutions per nucleotide position. 
belong to the same species, which presumably prevails in the human intestine. Phylogenetic analysis of these and other related sequences was performed and confirmed that strain YIT $12065^{\mathrm{T}}$ was phylogenetically most closely associated with members of the families of the order Clostridiales, but formed a separate cluster (Fig. 2).

On the basis of these phylogenetic and physiological data, strain YIT $12065^{\mathrm{T}}$ is proposed as the type strain of the novel taxon Christensenella minuta gen. nov., sp. nov. and Christensenella gen. nov. is proposed as the type genus of the novel family Christensenellaceae fam. nov. within the order Clostridiales of the phylum Firmicutes.

\section{Description of Christensenella gen. nov.}

Christensenella (Chris.ten.se.nel'la. N.L. fem. dim. n. Christensenella named after Professor Henrik Christensen, in honour of his many contributions to systematic bacteriology).

Cells are Gram-negative, strictly anaerobic, non-sporeforming, non-motile, short rods. Utilize various sugars and produce volatile fatty acids as fermentation end products. The type species is Christensenella minuta.

\section{Description of Christensenella minuta sp. nov.}

Christensenella minuta (mi.nu'ta. L. fem. adj. minuta little, small, minute, referring to the cell and colony size).

Displays the following properties in addition to those given for the genus. Cells are approximately $0.4 \times 0.8-1.9 \mu \mathrm{m}$ and occur singly or in pairs. Colonies after 4 days of growth at $37{ }^{\circ} \mathrm{C}$ on modified GAM agar under anaerobic conditions are $0.1 \mathrm{~mm}$ in diameter, circular and beige. Grows at 25$43{ }^{\circ} \mathrm{C}$, with optimum growth at $37-40{ }^{\circ} \mathrm{C}$. The $\mathrm{pH}$ range for growth at $37^{\circ} \mathrm{C}$ is $\mathrm{pH} 6.0-9.0$, with optimal growth at $\mathrm{pH}$ 7.5. Resistant to $20 \%$ bile. No growth is observed on medium containing $\geqslant 5 \% \mathrm{NaCl}$. Major end products of metabolism of glucose are acetic and butyric acids. Negative for aesculin hydrolysis, catalase, gelatin hydrolysis, indole production, nitrate reduction, oxidase and urease. Acid is produced from glucose, salicin, D-xylose, L-arabinose and Lrhamnose. Acid is produced weakly from D-mannose. Acid is not produced from cellobiose, D-mannitol, melezitose, raffinose, D-sorbitol, trehalose, glycerol, lactose, maltose or sucrose. By using API test systems (API Rapid ID 32A and API ZYM), positive reactions are obtained for $\alpha$-arabinosidase, $\beta$-galactosidase, $\beta$-glucosidase, glutamic acid decarboxylase and naphthol-AS-BI-phosphohydrolase. Negative for $N$-acetyl- $\beta$-glucosaminidase, acid and alkaline phosphatases, alanine arylamidase, arginine arylamidase, arginine dihydrolase, chymotrypsin, cystine arylamidase, esterase (C4), esterase lipase (C8), $\alpha$-fucosidase, $\alpha$-galactosidase, $\alpha$ glucosidase, $\beta$-glucuronidase, glutamyl glutamic acid arylamidase, glycine arylamidase, histidine arylamidase, leucine arylamidase, leucyl glycine arylamidase, lipase (C14), $\alpha$ mannosidase, phenylalanine arylamidase, 6-phosphate$\beta$-galactosidase, proline arylamidase, pyroglutamic acid arylamidase, serine arylamidase, trypsin, tyrosine arylamidase and valine arylamidase. Dominant cellular fatty acids of cells grown on PYG agar at $37{ }^{\circ} \mathrm{C}$ are iso- $\mathrm{C}_{15: 0}, \mathrm{C}_{16: 0}$ and $\mathrm{C}_{14: 0}$. Respiratory quinones are not detected. The cell wall contains glutamic acid, serine, alanine and LL- $\mathrm{A}_{2} \mathrm{pm}$. Wholecell sugars are ribose, rhamnose, galactose and glucose.

The type strain, YIT $12065^{\mathrm{T}}\left(=\mathrm{DSM} 22607^{\mathrm{T}}=\mathrm{JCM}\right.$ $\left.16072^{\mathrm{T}}\right)$, was isolated from human faeces. The DNA $\mathrm{G}+\mathrm{C}$ content of the type strain is $51.3 \mathrm{~mol} \%$.

\section{Description of Christensenellaceae fam. nov.}

Christensenellaceae (Chris.ten.se.nel.la'ce.a.e. N.L. fem. n. Christensenella type genus of the family; suff. -aceae ending to denote a family; N.L. fem. pl. n. Christensenellaceae family of the genus Christensenella).

The family is described on the basis of phylogenetic analyses of $16 \mathrm{~S}$ rRNA gene sequences. Cells are rodshaped, Gram-negative and anaerobic. Belong to the order Clostridiales within the class Clostridia of the phylum Firmicutes. The type genus is Christensenella.

\section{Acknowledgements}

We are grateful to Dr Jean P. Euzéby of the Ecole Nationale Vétérinaire, Toulouse, for his suggestions regarding the etymology of the species epithet. We thank H. Sakon and K. Manabe for their advice and help with the quinone analysis, K. Kimura, Y. Mori and T. Yamada for the cell sugar analysis and M. Ando and C. Hata for helping with the electron micrographs. We also thank Drs Ryuichiro Tanaka and Haruji Sawada for their understanding and encouragement through our research activities.

\section{References}

Chonan, O., Matsumoto, K. \& Watanuki, M. (1995). Effect of galactooligosaccharides on calcium absorption and preventing bone loss in ovariectomized rats. Biosci Biotechnol Biochem 59, 236-239.

Eckburg, P. B., Bik, E. M., Bernstein, C. N., Purdom, E., Dethlefsen, L., Sargent, M., Gill, S. R., Nelson, K. E. \& Relman, D. A. (2005). Diversity of the human intestinal microbial flora. Science 308, 1635-1638.

Ezaki, T., Saidi, S. M., Liu, S. L., Hashimoto, Y., Yamamoto, H. \& Yabuuchi, E. (1990). Rapid procedure to determine the DNA base composition from small amounts of gram-positive bacteria. FEMS Microbiol Lett 67, 127-130.

Felsenstein, J. (2004). PHYLIP (phylogeny inference package) version 3.6. Distributed by the author. Department of Genome Sciences, University of Washington, Seattle, USA.

Guindon, S. \& Gascuel, O. (2003). A simple, fast, and accurate algorithm to estimate large phylogenies by maximum likelihood. Syst Biol 52, 696-704.

Holdeman, L. V., Cato, E. P. \& Moore, W. E. C. (1977). Anaerobe Laboratory Manual, 4th edn. Blacksburg, VA: Virginia Polytechnic Institute and State University.

Honda, S., Akao, E., Suzuki, S., Okuda, M., Kakehi, K. \& Nakamura, J. (1989). High-performance liquid chromatography of reducing carbohydrates as strongly ultraviolet-absorbing and electrochemically sensitive 1-phenyl-3-methyl-5-pyrazolone derivatives. Anal Biochem 180, 351-357. 
Katsuta, A., Adachi, K., Matsuda, S., Shizuri, Y. \& Kasai, H. (2005). Ferrimonas marina sp. nov. Int J Syst Evol Microbiol 55, 1851-1855.

Kim, S., Jeong, H., Kim, S. \& Chun, J. (2006). Clostridium ganghwense sp. nov., isolated from tidal flat sediment. Int J Syst Evol Microbiol 56, 691-693.

Kimura, M. (1980). A simple method for estimating evolutionary rates of base substitutions through comparative studies of nucleotide sequences. J Mol Evol 16, 111-120.

Komagata, K. \& Suzuki, K. (1987). Lipid and cell-wall analysis in bacterial systematics. Methods Microbiol 19, 161-207.

Kuykendall, L. D., Roy, M. A., O’Neill, J. J. \& Devine, T. E. (1988). Fatty acids, antibiotic resistance, and deoxyribonucleic acid homology groups of Bradyrhizobium japonicum. Int J Syst Bacteriol 38, 358-361.

Ley, R. E., Turnbaugh, P. J., Klein, S. \& Gordon, J. I. (2006). Microbial ecology: human gut microbes associated with obesity. Nature 444, 1022-1023.

Ley, R. E., Hamady, M., Lozupone, C., Turnbaugh, P. J., Ramey, R. R., Bircher, J. S., Schlegel, M. L., Tucker, T. A., Schrenzel, M. D. \& other authors (2008). Evolution of mammals and their gut microbes. Science 320, 1647-1651.

Lipman, D. J. \& Pearson, W. R. (1985). Rapid and sensitive protein similarity searches. Science 227, 1435-1441.

Miller, L. T. (1982). Single derivatization method for routine analysis of bacterial whole-cell fatty acid methyl esters, including hydroxy acids. J Clin Microbiol 16, 584-586.

Morotomi, M., Nagai, F., Sakon, H. \& Tanaka, R. (2008). Dialister succinatiphilus sp. nov. and Barnesiella intestinihominis sp. nov., isolated from human faeces. Int J Syst Evol Microbiol 58, 2716-2720.

Morotomi, M., Nagai, F., Sakon, H. \& Tanaka, R. (2009). Paraprevotella clara gen. nov., sp. nov. and Paraprevotella xylaniphila sp. nov., members of the family 'Prevotellaceae' isolated from human faeces. Int J Syst Evol Microbiol 59, 1895-1900.

Morotomi, M., Nagai, F., Watanabe, Y. \& Tanaka, R. (2010). Succinatimonas hippei gen. nov., sp. nov., isolated from human faeces. Int J Syst Evol Microbiol 60, 1788-1793.

Morotomi, M., Nagai, F. \& Watanabe, Y. (2011). Parasutterella secunda sp. nov., isolated from human faeces and proposal of Sutterellaceae fam. nov. in the order Burkholderiales. Int J Syst Evol Microbiol 61, 637-643.

Nagai, F., Morotomi, M., Sakon, H. \& Tanaka, R. (2009). Parasutterella excrementihominis gen. nov., sp. nov., a member of the family Alcaligenaceae isolated from human faeces. Int J Syst Evol Microbiol 59, 1793-1797.

Nagai, F., Morotomi, M., Watanabe, Y., Sakon, H. \& Tanaka, R. (2010a). Alistipes indistinctus sp. nov. and Odoribacter laneus sp. nov., common members of the human intestinal microbiota isolated from faeces. Int J Syst Evol Microbiol 60, 1296-1302.

Nagai, F., Watanabe, Y. \& Morotomi, M. (2010b). Slackia piriformis sp. nov. and Collinsella tanakaei sp. nov., new members of the family Coriobacteriaceae, isolated from human faeces. Int J Syst Evol Microbiol 60, 2639-2646.

Page, R. D. M. (1996). TreeView: an application to display phylogenetic trees on personal computers. Comput Appl Biosci 12, 357-358.

Pikuta, E. V., Hoover, R. B., Bej, A. K., Marsic, D., Detkova, E. N., Whitman, W. B. \& Krader, P. (2003). Tindallia californiensis sp. nov., a new anaerobic, haloalkaliphilic, spore-forming acetogen isolated from Mono Lake in California. Extremophiles 7, 327-334.

Qin, J., Li, R., Raes, J., Arumugam, M., Burgdorf, K. S., Manichanh, C., Nielsen, T., Pons, N., Levenez, F. \& other authors (2010). A human gut microbial gene catalogue established by metagenomic sequencing. Nature 464, 59-65.

Ramamoorthy, S., Sass, H., Langner, H., Schumann, P., Kroppenstedt, R. M., Spring, S., Overmann, J. \& Rosenzweig, R. F. (2006). Desulfosporosinus lacus sp. nov., a sulfate-reducing bacterium isolated from pristine freshwater lake sediments. Int J Syst Evol Microbiol 56, 2729-2736.

Saitou, N. \& Nei, M. (1987). The neighbor-joining method: a new method for reconstructing phylogenetic trees. Mol Biol Evol 4, 406-425.

Sakon, H., Nagai, F., Morotomi, M. \& Tanaka, R. (2008). Sutterella parvirubra sp. nov. and Megamonas funiformis sp. nov., isolated from human faeces. Int J Syst Evol Microbiol 58, 970-975.

Schleifer, K. H. (1985). Analysis of the chemical composition and primary structure of murein. Methods Microbiol 18, 123-156.

Stackebrandt, E., Schumann, P., Schüler, E. \& Hippe, H. (2003). Reclassification of Desulfotomaculum auripigmentum as Desulfosporosinus auripigmenti corrig., comb. nov. Int J Syst Evol Microbiol 53, 1439-1443.

Tamura, K., Dudley, J., Nei, M. \& Kumar, S. (2007). MEGA4: molecular evolutionary genetic analysis (MEGA) software version 4.0. Mol Biol Evol 24, 1596-1599.

Tap, J., Mondot, S., Levenez, F., Pelletier, E., Caron, C., Furet, J. P., Ugarte, E., Muñoz-Tamayo, R., Paslier, D. L. \& other authors (2009). Towards the human intestinal microbiota phylogenetic core. Environ Microbiol 11, 2574-2584.

Thompson, J. D., Gibson, T. J., Plewniak, F., Jeanmougin, F. \& Higgins, D. G. (1997). The CLUSTAL_X windows interface: flexible strategies for multiple sequence alignment aided by quality analysis tools. Nucleic Acids Res 25, 4876-4882.

Tsukinowa, E., Karita, S., Asano, S., Wakai, Y., Oka, Y., Furuta, M. \& Goto, M. (2008). Fecal microbiota of a dugong (Dugong dugong) in captivity at Toba Aquarium. J Gen Appl Microbiol 54, 25-38.

Turnbaugh, P. J., Hamady, M., Yatsunenko, T., Cantarel, B. L., Duncan, A., Ley, R. E., Sogin, M. L., Jones, W. J., Roe, B. A. \& other authors (2009). A core gut microbiome in obese and lean twins. Nature 457, 480-484.

Vatsurina, A., Badrutdinova, D., Schumann, P., Spring, S. \& Vainshtein, M. (2008). Desulfosporosinus hippei sp. nov., a mesophilic sulfate-reducing bacterium isolated from permafrost. Int J Syst Evol Microbiol 58, 1228-1232.

Watanabe, Y., Nagai, F., Morotomi, M., Sakon, H. \& Tanaka, R. (2010). Bacteroides clarus sp. nov., Bacteroides fluxus sp. nov. and Bacteroides oleiciplenus sp. nov., isolated from human faeces. Int J Syst Evol Microbiol 60, 1864-1869.

Whitman, W. B. (2006). Error in $\mathrm{G}+\mathrm{C}$ calculations. Int J Syst Evol Microbiol 56, 1177.

Yokoyama, H., Wagner, I. D. \& Wiegel, J. (2010). Caldicoprobacter oshimai gen. nov., sp. nov., an anaerobic, xylanolytic, extremely thermophilic bacterium isolated from sheep faeces, and proposal of Caldicoprobacteraceae fam. nov. Int J Syst Evol Microbiol 60, 67-71.

Zhang, C., Liu, X. \& Dong, X. (2004). Syntrophomonas curvata sp. nov., an anaerobe that degrades fatty acids in co-culture with methanogens. Int J Syst Evol Microbiol 54, 969-973.

Zhang, C., Liu, X. \& Dong, X. (2005). Syntrophomonas erecta sp. nov., a novel anaerobe that syntrophically degrades short-chain fatty acids. Int J Syst Evol Microbiol 55, 799-803.

Zoetendal, E. G., Rajilic-Stojanovic, M. \& de Vos, W. M. (2008). Highthroughput diversity and functionality analysis of the gastrointestinal tract microbiota. Gut 57, 1605-1615. 